Regular paper

\title{
Assembly and function of the Photosystem II manganese stabilizing protein: lessons from its natively unfolded behavior
}

\author{
Aaron J. Wyman ${ }^{1} \&$ Charles F. Yocum ${ }^{1,2, *}$ \\ ${ }^{1}$ Department of Molecular, Cellular, and Developmental Biology; ${ }^{2}$ Department of Chemistry, The University of \\ Michigan-Ann Arbor, Ann Arbor, MI 48109, USA; *Author for correspondence (e-mail: cyocum@umich.edu; \\ fax: + 1-734-647-0884)
}

Received 16 December 2004; accepted in revised form 16 December 2004

Key words: manganese stabilizing protein, natively unfolded protein, Photosystem II, thermostability

\begin{abstract}
The Photosystem II (PS II) manganese stabilizing protein (MSP) possesses characteristics, including thermostability, ascribed to the natively unfolded class of proteins (Lydakis-Simantiris et al. (1999) Biochemistry 38: 404-414). A site-directed mutant of MSP, C28A, C51A, which lacks the -S-S- bridge, also binds to PS II at wild-type levels and reconstitutes oxygen evolution activity [Betts et al. (1996) Biochim Biophys Acta 1274: 135-142], although the mutant protein is even more disordered in solution. Both WT and C28A, C51A MSP aggregate upon heating, but an examination of the effects of protein concentration and $\mathrm{pH}$ on heat-induced aggregation showed that each MSP species exhibited greater resistance to aggregation at a $\mathrm{pH}$ near their $\mathrm{p} I$ (5.2) than do either bovine serum albumin (BSA) or carbonic anhydrase, which were used as model water soluble proteins. Increases in $\mathrm{pH}$ above the $\mathrm{p} I$ of the MSPs and BSA enhanced their aggregation resistance, a behavior which can be predicted from their charge (MSP) or a combination of charge and stabilization by -S-S- bonds (BSA). In the case of aggregation resistance by MSP, this is likely to be an important factor in its ability to avoid unproductive self-association reactions in favor of formation of the protein-protein interactions that lead to formation of the functional oxygen evolving complex.
\end{abstract}

Abbreviations: BSA - bovine serum albumin; CD - circular dichroism; IPTG - isopropyl- $\beta$-D-thiogalactopyranoside; MSP - manganese stabilizing protein; OEC - $\mathrm{O}_{2}$-evolving complex; PAGE - polyacrylamide gel electrophoresis; PS - Photosystem; $p s b O$ - gene encoding precursor MSP; WT - wild-type

\section{Introduction}

Photosystem II (PS II) is unique in its polypeptide composition, consisting of several intrinsic and extrinsic proteins, along with a tetranuclear $\mathrm{Mn}$ cluster, and inorganic cofactors $\left(\mathrm{Ca}^{+2}\right.$ and $\left.\mathrm{Cl}^{-}\right)$ (Debus 1992). The membrane-bound intrinsic proteins of PS II form a core structure that provides binding sites for both the inorganic cofactors and water-soluble extrinsic proteins (MSP, 23, and
$17 \mathrm{kDa}$ in eukaryotes) (Debus 1992; Seidler 1996). In solution, MSP has properties similar to natively unfolded proteins (Lydakis-Simantiris et al. 1999), which have unique physical and chemical characteristics, including thermostability, extreme $\mathrm{p} I$ values, extended solution structures, and anomalous mobility on SDS-PAGE. These proteins are found as components of multisubunit complexes that have diverse activities (protein phosphorylation, ribosomal translation, synapse formation, 
cytoskeletal structure) (Weinreb et al. 1996). MSP possesses a low $\mathrm{p} I(5.2)$, a relatively high content of random coil and turn (50-55\%) (Xu et al. 1994; Ahmed et al. 1995; Shutova et al. 1997; LydakisSimantiris et al. 1999), and exhibits deviations in estimated molecular mass that range from $26.5 \mathrm{kDa}$ (DNA sequencing, MALDI-TOF mass spectrometry (Betts et al. 1994; Zubrzycki et al. 1998; Svensson et al. 2002)), to $33 \mathrm{kDa}$ (SDSPAGE) and 34-41 kDa (gel filtration) (Kuwabara and Murata 1979; Popelkova et al. 2002a). These properties, combined with MSP's thermostability (Lydakis-Simantiris et al. 1999) are similar to those possessed by proteins that are said to be natively denatured or intrinsically disordered. A mutant of MSP (C28A, C51A) lacking the single -S-S- bridge of the WT protein (Betts et al. 1996) is also thermostable, although it has a larger apparent mass (51 kDa; data not shown). Here, we show that the thermostability of these MSP species is directly related to their ability to resist protein aggregation upon heating. This behavior may, in turn, be an essential feature of MSP's solution structure that enables it to bind selectively to PS II, rather than forming unproductive protein aggregates.

\section{Materials and methods}

Recombinant MSPs were overexpressed, isolated, and purified as described previously (Betts et al. 1994,1996; Popelkova et al. 2002b, 2003a), except that the LB growth medium contained only ampicillin $\left(50 \mu \mathrm{g} \mathrm{ml}^{-1}\right)$, and $25-32.5 \mu \mathrm{M}$ IPTG was used to induce protein overexpression. Purified proteins were stored in the solubilization buffer used for protein isolation $(3 \mathrm{M}$ urea, $20 \mathrm{mM}$ Bis-Tris (pH 6.4), $5 \mathrm{mM} \mathrm{NaCl}$ ), or in SMN buffer (0.4 M sucrose, $50 \mathrm{mM}$ Mes (pH 6.0), $10 \mathrm{mM} \mathrm{NaCl}$ ); urea was removed by dialysis against SMN buffer. MSP concentrations were determined spectrophotometrically (Xu and Bricker 1992). BSA and carbonic anhydrase were purchased from Sigma-Aldrich, and their concentrations were determined spectrophotometrically (Lindskog 1960; Wetlaufer 1962). For CD

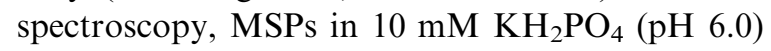
were analyzed as previously described (Popelkova et al. 2002a). The time dependence of protein aggregation was assayed by incubation of proteins at $90{ }^{\circ} \mathrm{C}$ for up to $5 \mathrm{~min}$ in $\mathrm{SMN}$ (pH 5.3); after cooling, aggregates were removed by centrifugation, and the protein concentration of the supernatant was determined spectrophotometrically. The concentration dependence of heat-induced protein aggregation was characterized in a similar manner, but proteins were incubated at $90{ }^{\circ} \mathrm{C}$ for $20 \mathrm{~min}$ in buffers containing $0.4 \mathrm{M}$ sucrose, $10 \mathrm{mM} \mathrm{NaCl}$, and either $50 \mathrm{mM}$ MES (pH 5.3), Tris (pH 6), or $\mathrm{KH}_{2} \mathrm{PO}_{4}(\mathrm{pH} 5.7$ or 7.7). The $\mathrm{pH}$ values are those of the buffers at $90{ }^{\circ} \mathrm{C}$, as determined from their temperature coefficients. The soluble protein concentration was determined as described above.

\section{Results and discussion}

Effect of heating on the near-UV CD spectra of wild-type and C28A, C51A MSP

The near-UV CD spectrum of WT MSP has well defined peaks that are assigned to Tyr (at $285 \mathrm{~nm}$ ) and the lone Trp (W241) at $291 \mathrm{~nm}$ (Figure 1a). Additional minor peaks at 258 and $264 \mathrm{~nm}$ are assigned to Phe. Near-UV CD signals from these aromatic residues are taken as indicators of the integrity of a protein's tertiary structure; hydrophobic environments enhance the signals, while increased hydrophilicity leads to decreased signal intensities (Kelly and Price 1997). These CD features are absent in C28A, C51A MSP (Figure 1b); this observation, when combined with the mutant protein's estimated mass from gel filtration (51 kDa; data not shown), indicates that loss of the -S-S- bridge has created additional disorder in its solution structure. Heated WT MSP (Figure 1a) has no near-UV CD features and possesses a spectrum similar to that of C28A, C51A MSP at $25^{\circ} \mathrm{C}$ (Figure $1 \mathrm{~b}$ ), indicating that the mutant's room temperature disordered state can be achieved by heating WT MSP to $90{ }^{\circ} \mathrm{C}$. WT MSP regains its initial near-UV CD signals upon cooling whereas neither heating nor subsequent cooling affect the spectrum of the mutant (Figure 1b).

\section{Time course of heat-induced aggregation of MSP and model water-soluble proteins}

Two reconstitutively active MSP species that differ in their extent of structural disorder provided an opportunity to further examine the intrinsic 

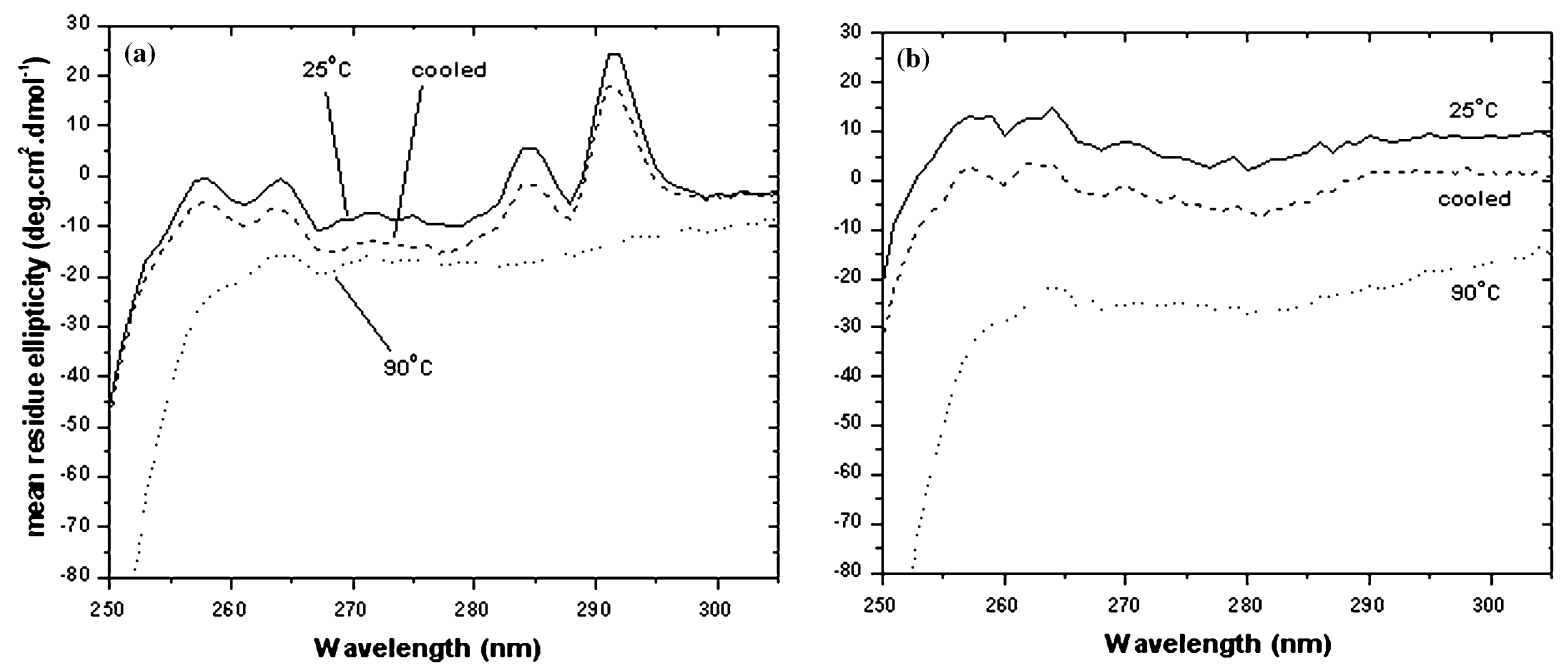

Figure 1. Near-UV CD spectra of WT and C28A, C51A MSP. The spectra are averages of 20 scans each. Experimental conditions: scan width, 320-250 nm; time constant, $1 \mathrm{~s}$; bandwidth, $1 \mathrm{~nm}$; path length, $1 \mathrm{~cm}$.

thermostability of MSP; BSA and carbonic anhydrase were utilized as standards of comparison. BSA $(66 \mathrm{kDa})$ is stabilized by $17-\mathrm{S}-\mathrm{S}$ bridges, and has a $\mathrm{p} I$ of 5.0, close to that of MSP, while carbonic anhydrase $(29 \mathrm{kDa})$ has a mass comparable to that of MSP but contains no -S-Sbonds and has a $\mathrm{p} I$ of 6.6. The heat-induced aggregation behavior of each model protein has been characterized (Alexander and Hamilton 1960; Wetzel et al. 1980; Peters Jr. 1996; Rajaraman et al. 1996; Kundu and Guptasarma 1999). The time dependence of heat-induced aggregation (Figure 2) shows that after 1 min of heating, 45$50 \%$ of the MSP species remained soluble, while only $35 \%$ of carbonic anhydrase and $10 \%$ of BSA resisted aggregation. Prolonged heating further decreased the concentration of soluble carbonic anhydrase ( $10 \%$ by $5 \mathrm{~min}$ ), while the amount of soluble BSA remained constant at about $10 \%$. Heating beyond $1 \mathrm{~min}$ had little effect on the solubilities of unaggregated WT and C28A, C51A MSP (Figure 2).

\section{Effect of $p H$ and protein concentration on resistance to heat-induced protein aggregation}

A protein's net charge and concentration should affect the extent to which it self-aggregates. Figure 3a presents the heat-induced aggregation behaviors of WT MSP in buffers over a $\mathrm{pH}$ range from 5.3 to 7.7 , and at concentrations up to
$50 \mu \mathrm{M}$. The $\mathrm{pH}$ values given in the figures are adjusted to $90{ }^{\circ} \mathrm{C}$ using the buffers' temperature coefficients. At pH 5.3, WT MSP exhibits resistance to aggregation at low concentrations, whereas above $30 \mu \mathrm{M}$ about $50 \%$ of the protein remained in solution after heating. Increasing the $\mathrm{pH}$ to values above the $\mathrm{p} I$ of WT MSP produces a marked increase in the amount of aggregationresistant protein (90-95\%) for all concentrations tested. This is likely to be due predominantly to an

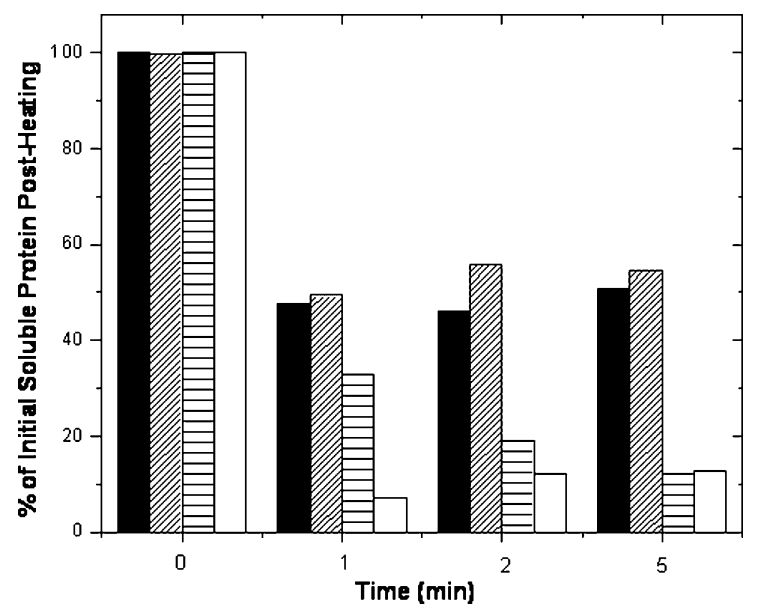

Figure 2. Time course of heat-induced aggregation of MSPs, BSA and carbonic anhydrase. Aggregation was determined as described in Materials and methods. Symbols are: WT MSP $(31.5 \mu \mathrm{M})$, solid; C28A, C51A MSP $(11.9 \mu \mathrm{M})$, diagonal stripes; carbonic anhydrase $(30.4 \mu \mathrm{M})$, horizontal stripes; BSA $(34.5 \mu \mathrm{M})$, clear. 

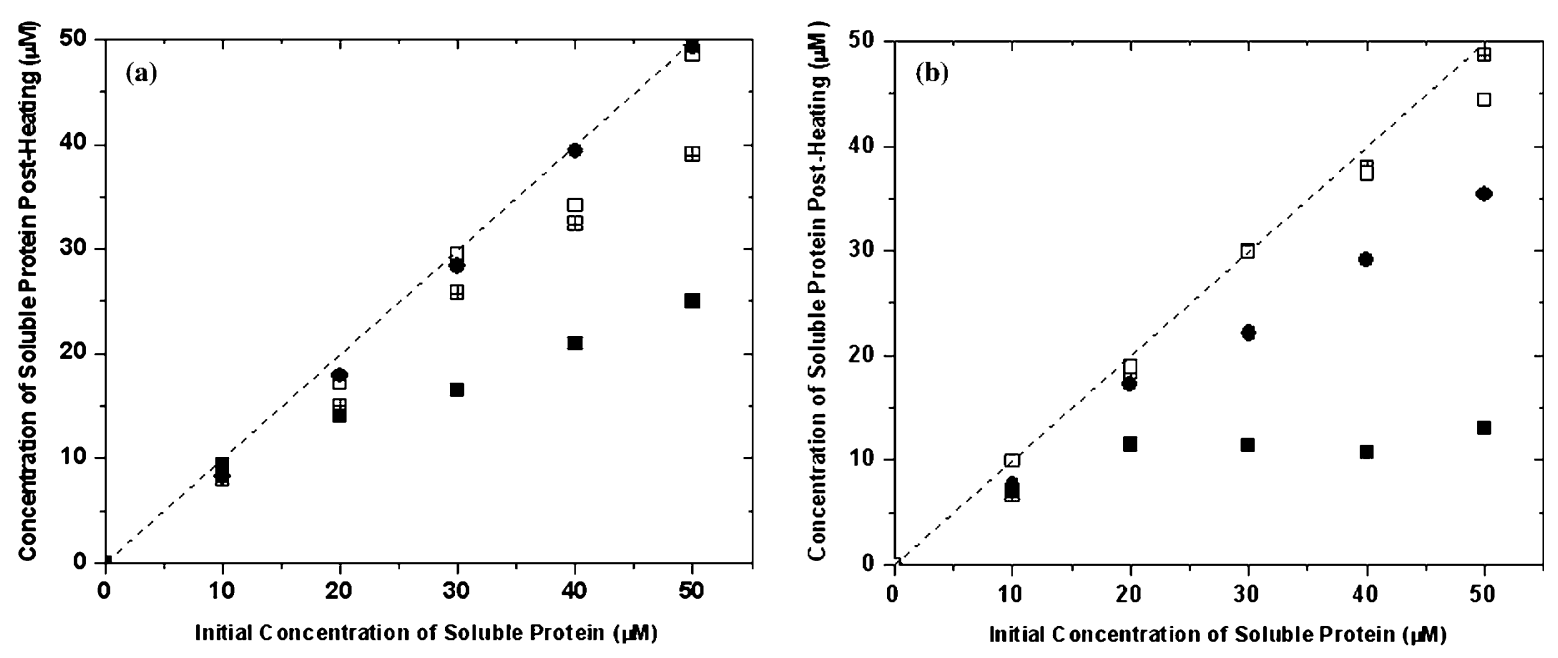

Figure 3. Effect of pH on the aggregation of WT MSP (a) and C28A, C51A MSP (b). The symbols are: MES, pH 5.3, (- $)$; $\mathrm{KH}_{2} \mathrm{PO}_{4}$, pH 5.7, (๑); TRIS, pH 6.0, (田); $\mathrm{KH}_{2} \mathrm{PO}_{4}, \mathrm{pH} 7.7,(\square)$. The dashed line is the result that would be obtained if no protein aggregation were to occur.

increased negative net charge on MSP, which would increase the repulsion between individual protein molecules in solution and in turn limit opportunities for protein-protein interactions that might initiate the formation of complexes that result in insoluble aggregates. A similar experiment with C28A, C51A MSP (Figure 3b) showed that it also resists aggregation at low protein concentrations, but at $\mathrm{pH} 5.3$, only $12-15 \mu \mathrm{M}$ protein remains soluble, regardless of the initial concentration present in solution. With increasing $\mathrm{pH}$, however, C28A, C51A MSP also exhibits increased resistance to aggregation, attaining 95$100 \%$ solubility at $\mathrm{pH} 7.7$ for all concentrations tested at $90{ }^{\circ} \mathrm{C}$.

Figure 4 compares the aggregation resistance of both MSP species to a pair of model water soluble proteins at two $\mathrm{pH}$ values. At $\mathrm{pH} 5.3$ (Figure 4a), BSA and carbonic anhydrase exhibit limited solubility after heating, even at the lowest
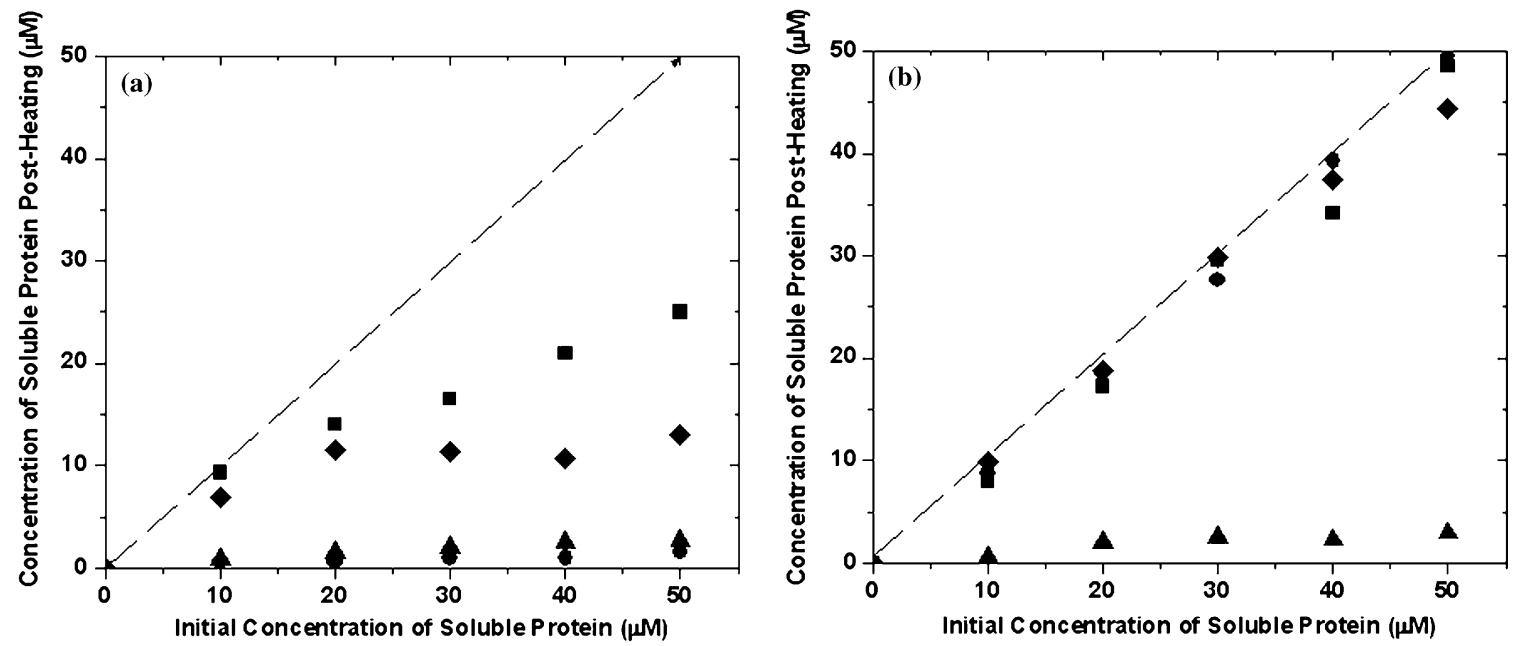

Figure 4. A comparison of aggregation properties of MSPs, BSA, and carbonic anhydrase at pH 5.3 (a) or 7.7 (b). The symbols are:

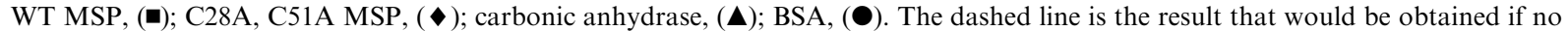
protein aggregation were to occur. 
concentrations used. Little, if any, additional protein remains in solution as their concentrations are increased. When the $\mathrm{pH}$ was increased to 7.7 (Figure 4b), carbonic anhydrase showed no change in its aggregation behavior (5-10\% remained soluble after heating). However, BSA showed an increased resistance to aggregation comparable to that of both of the MSP species. This can be explained by the increased charge present on BSA at $\mathrm{pH} 7.7$, which normally leads to an increase in its solubility in aqueous buffers, while also acting to prevent interactions between BSA molecules (Hughes 1954; Peters Jr. 1996). However, BSA is not thermostable at a $\mathrm{pH}$ near its $\mathrm{p} I$, in spite of the presence of $17-\mathrm{S}-\mathrm{S}$ - bridges to impart structural stability to the protein. In agreement with other data on BSA (Militello et al. 2004), the results in Figure 4b shows that some 'normally folded' proteins become more heatstable as they are shifted away from their $\mathrm{p} I$ values. In contrast, MSP proved to be innately thermostable, even at a $\mathrm{pH}$ near its $\mathrm{p} I$ value.

Extensive cataloging of intrinsically disordered proteins (Dunker et al. 2001) shows that these polypeptides enter into protein-protein, proteinnucleic acid or protein-small ligand interactions. Their thermostability is probably a byproduct of the high ratio of charged to hydrophobic amino acids in these proteins, which imparts disorder to their solution structures (Uversky 2000; Dunker et al. 2001; Popelkova et al. 2003b). The high charge on these structures, reflected in the extreme $\mathrm{p} I$ values of such proteins, is also a consequence of this distribution of amino acid residues. The resulting disordered structures have highly flexible conformations in solution, and it is proposed that this feature of natively unfolded proteins is essential to permit them to form initial complexes with their docking partners and undergo the subsequent folding maneuvers that form the more organized mature protein complex (Weinreb et al. 1996; Denning et al. 2002; Permyakov et al. 2003).

Here we have shown that MSP's thermostability is due to its ability to resist aggregation, which may be an emergent property of natively unfolded proteins that can be linked to their high content of charged amino acids, thus allowing them to resist aggregation by charge repulsion. This property would permit high concentrations of a protein like MSP to be maintained in solution in an organelle compartment like the thylakoid lumen, because it can avoid formation of aggregates due to self association. High concentrations of soluble MSP enable rapid targeting of binding sites on PS II, permitting MSP to dock, fold, and assist in the binding of other extrinsic proteins and inorganic cofactors to form a highly active OEC.

\section{Acknowledgements}

Professor Yocum acknowledges with gratitude a long and productive exchange of data and ideas with Professor Norio Murata. This work was supported by NSF Grant MCB 0110455 to CFY.

\section{References}

Ahmed A, Tajmirriahi HA and Carpentier R (1995) A quantitative secondary structure-analysis of the $33-\mathrm{kDa}$ extrinsic polypeptide of Photosystem-II by FTIR spectroscopy. FEBS Lett 363: 65-68

Alexander P and Hamilton LDG (1960) Changes in the reactivity of disulfide bonds in bovine serum albumin on denaturation. Arch Biochem Biophys 88: 128-135

Betts SD, Hachigian TM, Pichersky E and Yocum CF (1994) Reconstitution of the spinach oxygen-evolving complex with recombinant Arabidopsis manganese-stabilizing protein. Plant Mol Biol 26: 117-130

Betts SD, Ross JR, Hall KU, Pichersky E and Yocum CF (1996) Functional reconstitution of Photosystem II with recombinant manganese-stabilizing proteins containing mutations that remove the disulfide bridge. Biochim Biophys Acta 1274: 135-142

Debus RJ (1992) The manganese and calcium-ions of photosynthetic oxygen evolution. Biochim Biophys Acta 1102: 269-352

Denning DP, Uversky V, Patel SS, Fink AL and Rexach M (2002) The Saccharomyces cerevisiae nucleoporin Nup2p is a natively unfolded protein. J Biol Chem 277: 3344733455

Dunker AK, Lawson JD, Brown CJ, Williams RM, Romero P, Oh JS, Oldfield CJ, Campen AM, Ratliff CR, Hipps KW, Ausio J, Nissen MS, Reeves R, Kang H, Kissinger CR, Bailey RW, Griswold MD, Chiu M, Garner EC and Obradovic Z (2001) Intrinsically disordered protein. J Mol Graph 19: 26-59.

Hughes WL (1954) Interstitial proteins: the proteins of blood plasma and lymph. In: Neurath $\mathrm{C} \mathrm{H}$ and Bailey K (eds) The Proteins: Chemistry, Biological Activity, and Methods, Vol. IIB, pp 663-753. Academic Press, New York

Kelly SM and Price NC (1997) The application of circular dichroism to studies of protein folding and unfolding. Biochim Biophys Acta 1338: 161-185

Kundu B and Guptasarma P (1999) Hydrophobic dye inhibits aggregation of molten carbonic anhydrase during thermal unfolding and refolding. Proteins-Struct Funct Genet 37: $321-324$ 
Kuwabara T and Murata N (1979) Purification and characterization of 33 kiloDalton protein of spinach-chloroplasts. Biochim Biophys Acta 581: 228-236

Lindskog S (1960) Purification and properties of bovine erythrocyte carbonic anhydrase. Biochim Biophys Acta 39: 218-226

Lydakis-Simantiris N, Hutchison RS, Betts SD, Barry BA and Yocum CF (1999) Manganese stabilizing protein of Photosystem II is a thermostable, natively unfolded polypeptide. Biochemistry 38: 404-414

Militello V, Casarino C, Emanuele A, Giostra A, Pullara F and Leone M (2004) Aggregation kinetics of bovine serum albumin studied by FTIR spectroscopy and light scattering. Biophys Chem 107: 175-187

Permyakov SE, Millett IS, Doniach S, Permyakov EA and Uversky VN (2003) Natively unfolded C-terminal domain of caldesmon remains substantially unstructured after the effective binding to calmodulin. Proteins-Struct Funct Genet 53: $855-862$

Peters Jr. T (1996) All About Albumin: Biochemistry, Genetics, and Medical Applications. Academic Press, San Diego, CA

Popelkova H, Im MM, D'Auria J, Betts SD, Lydakis-Simantiris, N and Yocum CF (2002a). N-terminus of the Photosystem II manganese stabilizing protein: effects of sequence elongation and truncation. Biochemistry 41: 2702-2711

Popelkova H, Im MM and Yocum CF (2002b) N-terminal truncations of manganese stabilizing protein identify two amino acid sequences required for binding of the eukaryotic protein to Photosystem II and reveal the absence of one binding-related sequence in cyanobacteria. Biochemistry 41: 10038-10045

Popelkova H, Im MM and Yocum CF (2003a) Binding of manganese stabilizing protein to Photosystem II: identification of essential $\mathrm{N}$-terminal threonine residues and domains that prevent nonspecific binding. Biochemistry 42: 6193-6200

Popelkova H, Wyman A and Yocum C (2003b) Amino acid sequences and solution structures of manganese stabilizing protein that affect reconstitution of Photosystem II activity. Photosyn Res 77: 21-34

Rajaraman K, Raman B and Rao CM (1996) Molten-globule state of carbonic anhydrase binds to the chaperone-like alpha-crystallin. J Biol Chem 271: 27595-27600

Seidler A (1996) The extrinsic polypeptides of Photosystem II. Biochim Biophys Acta 1277: 35-60

Shutova T, Irrgang KD, Shubin V, Klimov VV and Renger G (1997) Analysis of pH-induced structural changes of the isolated extrinsic 33 KiloDalton protein of Photosystem II. Biochemistry 36: 6350-6358

Svensson B, Tiede DM and Barry BA (2002) Small-angle X-ray scattering studies of the manganese stabilizing subunit in Photosystem II. J Phys Chem B 106: 8485-8488

Uversky VN, Gillespie JR and Fink AL (2000) Why are "natively unfolded" proteins unstructured under physiologic conditions? Proteins-Struct Funct Genet 41: 415-427

Weinreb PH, Zhen WG, Poon AW, Conway KA and Lansbury PT (1996) NACP, a protein implicated in Alzheimer's disease and learning, is natively unfolded. Biochemistry 35 : 13709-13715

Wetlaufer DB (1962). Ultraviolet spectra of proteins and amino acids. Adv Prot Chem 17: 303-390

Wetzel R, Becker M, Behlke J, Billwitz H, Bohm S, Ebert B, Hamann H, Krumbiegel J and Lassmann G (1980) Temperature behavior of human serum albumin. Euro J Biochem 104: 469-478

$\mathrm{Xu}, \mathrm{Q}$ and Bricker TM (1992) Structural organization of proteins on the oxidizing side of Photosystem II - 2 molecules of the 33-kDa manganese stabilizing proteins per reaction center. J Biol Chem 267: 25816-25821

Xu Q, Nelson J and Bricker TM (1994) Secondary structure of the $33 \mathrm{kDa}$ extrinsic protein of Photosystem-II - a far-UV circular dichroism study. Biochim Biophys Acta 1188: 427-431

Zubrzycki IZ, Frankel LK, Russo PS and Bricker TM (1998) Hydrodynamic studies on the manganese-stabilizing protein of Photosystem II. Biochemistry 37: 13553-13558 